SESSION V: REACTIONS AND NERVE DAMAGE CHAIRPERSON: PROFESSOR W. CAIRNS S. SMITH 


\title{
The epidemiology of reactions and nerve damage
}

\author{
P. SAUNDERSON \\ American Leprosy Mission, Greenville, South Carolina, USA
}

\begin{abstract}
Summary The ALERT MDT Field Evaluation Study (AMFES) in Ethiopia, which was begun in 1988, involves the follow-up of 594 new patients for as long as 10 years after completion of treatment, including 6-monthly assessments of nerve function. In contrast to similar studies in India and Bangladesh, the Ethiopian cohort presented late, had a high rate of disability at diagnosis (55\%), a high rate of multibacillary disease $(51 \%)$ and a high rate of subsequent neuropathy (43\%). Preliminary findings include the following. One-third of the patients never exhibited nerve damage. True acute neuropathy has a very good prognosis when treated with a standard course of steroids; full recovery was observed in $88 \%$ of nerves. Chronic and recurrent neuropathy have a worse prognosis; these problems need to be identified early and managed appropriately, employing either new steroid regimens or new drugs. The risk factors identified in this study include, for neuropathy, older age, delay of diagnosis, thickened nerves at diagnosis, and reversal reactions. Risk factors for chronic or recurrent neuropathy include classification, impairment at diagnosis, and reversal and ENL reactions. Those factors associated with a poor outcome include impairment at diagnosis, and chronic or recurrent neuropathy. Various problems faced in research in the area of leprosy reactions and neuropathy are discussed, as are the priorities for research in the future.
\end{abstract}

\section{Introduction}

Nerve damage, perhaps the most important consequence of leprosy, is generally assumed to occur as a part of a reaction. The clinical features of reactions and nerve damage have been well described. ${ }^{1}$ However, there are many unanswered questions concerning the pathology and pathogenesis of nerve damage. ${ }^{2}$ Similarly, the epidemiology of nerve damage, in particular, its incidence, natural history, and the risk factors associated with it, are not well described. $^{3}$

Limiting factors have been the long natural history of the disease, which may be longer than 10 years, making comprehensive follow-up difficult to achieve; the study of varied patient cohorts, many hospital-based, with only a few studies based on patients in the field or on populations; the use of different methods of assessment of nerve function in different studies; application of different treatments; and diagnosis long after the process of nerve-damage had begun.

\section{Materials and methods}

The ALERT MDT Field Evaluation Study (AMFES) in Ethiopia, which was begun in 1988, 


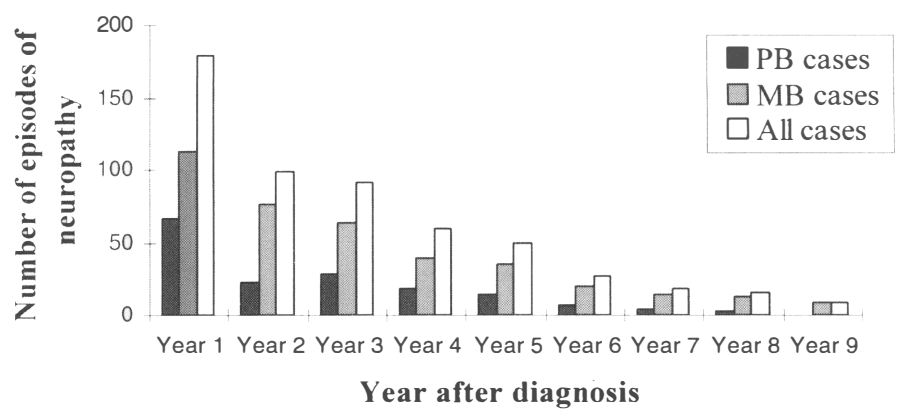

Figure 1. Number of episodes of neuropathy among 594 patients, by year after diagnosis.

involved the follow-up of 594 new patients for as long as 10 years after completion of treatment. Six-monthly nerve function assessments were done. In contrast to studies in India and Bangladesh, this cohort tended to present late, had a high rate of impairment at diagnosis (55\% for grades 1 and 2 combined), a high rate of multibacillary disease $(51 \%)$ and a high rate of subsequent neuropathy $(43 \%)$.

Multidrug therapy (MDT) was administered at monthly clinics, and, after completion of treatment, patients were examined every 6 months for as long as 10 years. Nervefunction was assessed and recorded at every visit, using simple, standardized voluntary muscle tests and sensory tests. New nerve function impairments could be treated at the clinic level with a standardized course of steroids. Referral to the ALERT Hospital was possible for complicated cases, although patients sometimes refused this because of the distance from home.

The general term 'neuropathy' is a clinical term, used here for any detectable abnormality in a particular peripheral nerve. It includes new nerve function impairment, such as a motor or sensory deficit, as well as pain and tenderness.



Figure 2. Incidence of episodes of neuropathy, by year after diagnosis. 
Table 1. Risk factors for any neuropathy. $\mathrm{CI}=$ confidence interval; $\mathrm{NS}=$ not significant $(P>0 \cdot 05)$; $\mathrm{PB}=$ paucibacillary; $\mathrm{MB}=$ multibacillary; $\mathrm{ENL}=$ erythema nodosum leprosum

\begin{tabular}{lcccc}
\hline Factor & \multicolumn{1}{c}{ Level } & $\begin{array}{c}\text { Numbers of } \\
\text { patients }\end{array}$ & Relative risk & $\begin{array}{c}\text { Multivariate } \\
\text { analysis }(95 \% \text { CI) }\end{array}$ \\
\hline Age group & $<20$ years & $89 / 177$ & 1 & $1 \cdot 5-3 \cdot 7$ \\
& $20-49$ years & $225 / 316$ & $2 \cdot 4^{*}$ & $2 \cdot 9-11 \cdot 5$ \\
Sex & $50+$ years & $85 / 101$ & $5 \cdot 8 *$ & NS \\
Delay & $<2$ years & $143 / 264$ & 1 & $1 \cdot 2-1 \cdot 7$ \\
PB/MB & $2+$ years & $254 / 324$ & $1 \cdot 4^{*}$ & \\
Thickened nerves & 0 & $38 / 98$ & 1 & $2 \cdot 2-6 \cdot 9$ \\
& $1-5+$ & $193 / 287$ & $3 \cdot 9 *$ & $3 \cdot 2-11 \cdot 7$ \\
Pregnancy & $6+$ & $168 / 209$ & $6 \cdot 1 *$ & \\
Reversal reaction & 0 & $305 / 496$ & 1 & $7 \cdot 2-62$ \\
ENL & + & $94 / 98$ & $21^{*}$ & \\
\hline
\end{tabular}

* Significant at the $95 \%$ level of confidence $(P \leq 0 \cdot 05)$.

\section{Results}

The timing and incidence of neuropathy are shown in Figures 1 and 2. Of 594 patients, 268 (45\%) had no impairment at diagnosis, but 73 of these patients developed neuropathy later during follow-up. Of the entire cohort, 195 patients (33\%) never developed any sign of neuropathy. Considering the longitudinal data for the 73 patients whose neuropathy occurred during regular surveillance, $41(56 \%)$ had single episodes of neuropathy, enduring less than 6

Table 2. Risk factors for chronic or recurrent neuropathy. Abbreviations as for Table 1. In addition, EHF $=$ eyeshands-feet

\begin{tabular}{|c|c|c|c|c|}
\hline Factor & Level & $\begin{array}{c}\text { Number of } \\
\text { patients }\end{array}$ & Relative risk & $\begin{array}{c}\text { Multivariate } \\
\text { analysis }(95 \% \mathrm{CI})\end{array}$ \\
\hline Age group & & & NS & \\
\hline Sex & & & NS & \\
\hline \multirow[t]{2}{*}{ Leprosy type } & PB & $43 / 294$ & 1 & \\
\hline & MB & $96 / 300$ & $1 \cdot 7 *$ & $1 \cdot 0-2 \cdot 9$ \\
\hline Leprosy & Borderline & $109 / 501$ & 1 & \\
\hline classification & Other & $30 / 93$ & $1.9 *$ & $1 \cdot 0-3 \cdot 6$ \\
\hline Delay & & & NS & \\
\hline \multirow{3}{*}{ EHF at diagnosis } & 0 & $32 / 268$ & 1 & \\
\hline & $1-2+$ & $43 / 157$ & $2 \cdot 8^{*}$ & $1 \cdot 5-5 \cdot 2$ \\
\hline & $3+$ & $64 / 169$ & $6 \cdot 4 *$ & $3 \cdot 4-12$ \\
\hline Thickened nerves & & & NS & \\
\hline Pregnancy & & & NS & \\
\hline Reversal & 0 & $80 / 496$ & 1 & \\
\hline reaction & + & $59 / 98$ & $10 \cdot 6 *$ & $6 \cdot 0-19$ \\
\hline \multirow{2}{*}{ ENL } & 0 & $127 / 578$ & 1 & \\
\hline & + & $12 / 16$ & $11 \cdot 6 *$ & $3 \cdot 1-43$ \\
\hline
\end{tabular}

\footnotetext{
* Significant at the $95 \%$ level of confidence $(P \leq 0 \cdot 05)$.
} 
Table 3. Risk factors for a poor outcome, defined as an EHF score $>0,5$ years after release from treatment. Abbreviations as for Table 2

\begin{tabular}{llccc}
\hline Factor & Level & $\begin{array}{c}\text { Number of } \\
\text { patients }\end{array}$ & Relative risk & $\begin{array}{c}\text { Multivariate } \\
\text { analysis }(95 \% \text { CI })\end{array}$ \\
\hline Age group & & NS & \\
Sex & & NS & \\
Leprosy type & & NS & \\
$\begin{array}{l}\text { Delay } \\
\text { Thickened nerves }\end{array}$ & 0 & NS & \\
EHF at diagnosis & $1-2+$ & $17 / 116$ & 1 & $4 \cdot 2-20$ \\
& $3+$ & $46 / 71$ & $9 \cdot 1^{*}$ & $18-225$ \\
Pregnancy & & $71 / 75$ & NS & \\
Reversal reaction & & & NS & \\
ENL & 0 & $62 / 169$ & 1 & $1 \cdot 5-9 \cdot 2$ \\
Chronic or & + & $72 / 93$ & $3 \cdot 7 *$ & \\
recurrent & & & & \\
neuropathy & & & & \\
\hline
\end{tabular}

* Significant at the $95 \%$ level of confidence $(P \leq 0 \cdot 05)$.

months, which responded well to treatment. Full recovery occurred in $88 \%$ of involved nerves when this was truly a single episode, with no evidence of previous impairment, and no subsequent episodes of clinically evident neuropathy. These episodes may be described as acute neuropathy.

Repeated episodes of neuropathy were common, occurring in $32(44 \%)$ of patients whose neuropathy developed after the start of MDT. We have arbitrarily defined 'chronic neuropathy' as the reappearance of symptoms or signs of neuropathy within 3 months of stopping treatment for neuropathy, and 'recurrent neuropathy' as the reappearance of symptoms or signs after a period of 3 months or more. The prognosis for chronic and recurrent neuropathy was worse than that for acute neuropathy, only $51 \%$ of involved nerves showing full recovery in the long-term after treatment. Significant risk factors for any neuropathy were greater age, longer delay of diagnosis, more thickened nerves at diagnosis, and the occurrence of reversal reaction (see also Tables 1-3). For chronic or recurrent neuropathy, important risk factors are multibacillary leprosy, greater impairment at diagnosis, the occurrence of reversal reaction, and the occurrence of ENL. For a poor outcome, defined as any impairment existing 5 years after completing treatment, risk factors are any impairment at diagnosis, and chronic or recurrent neuropathy.

\section{Discussion}

The incidence of neuropathy varies in different studies, but is perhaps greater in more recent studies, in which regular, detailed assessments of nerve function were carried out. Thus, in Bangladesh, a recently published study found an incidence of 34 episodes per 100 personyears at risk (PYAR) in MB patients during the first 6 months after diagnosis, ${ }^{4}$ a frequency very similar to that of 39 episodes per 100 PYAR found here.

The patients who never demonstrated evidence of nerve damage (33\%) are interesting. Because there appeared to be no relationship to the patients' classification, is there a genetic 
basis for this protection, or are patients being treated earlier? These patients are younger, were diagnosed after a shorter delay, exhibited fewer thickened nerves at the time of diagnosis, and did not experience reversal reactions.

Chronic and recurrent neuropathy have a worse prognosis; these patients need to be identified early and managed appropriately, either with new steroid regimens or with new anti-inflammatory or immunosuppressive drugs.

\section{Research priorities}

An important priority is definition of terms (neuritis, neuropathy, and nerve damage - acute, chronic, recurrent, late and silent) and standardization of methods of assessment and recording. The relationship of neuropathy to underlying pathological processes, including reactions, needs to be investigated. The frequency of occurrence of neuropathy and its natural history in different geographical settings should be further studied. Risk factors for the different types of reaction and neuropathy require further research, as do techniques for the early diagnosis of neuropathy, including diagnosis of the category of neuropathy.

\section{References}

1 Rose P, Waters MF. Reversal reactions in leprosy and their management. Lepr Rev, 1991; 62: 113-121.

2 van Brakel WH, Khawas IB. Silent neuropathy in leprosy: a n epidemiological description. Lepr Rev, 1994; 65: $350-360$.

3 Leinhardt C, Fine PEM. Type 1 reaction, neuritis and disability in leprosy. What is the current epidemiological situation? Lepr Rev, 1994; 65: 9-33.

4 Croft RP, Nicholls PG, Richardus JH, Smith WC. Incidence rates of acute nerve function impairment in leprosy: a prospective cohort analysis after 24 months (The Bangladesh Acute Nerve Damage Study). Lepr Rev, 2000; 71: $18-33$.

\section{DISCUSSION}

Dr Rambukkana: Was silent neuropathy observed in your study?

Dr Saunderson: If one defines silent neuropathy as impairment of nerve function without pain, tenderness and symptoms of reaction, silent neuropathy was observed among as many as $40-50 \%$ of the patients. Patients who experienced episodes of both silent neuropathy and neuropathy that was not silent were not uncommon.

Dr van Brakel: You defined chronic and recurrent neuropathy. How do you define acute neuropathy? I ask because the results of steroid therapy that you have presented are considerably better than those I will present. What do you think is the reason?

Dr Saunderson: Acute neuropathy was defined as that with onset within the preceding 6 months, according to the patient's statement, if the patient had been examined earlier, with evidence of neuropathy occurring during the preceding 6 months. I think that the prime reason for the difference between our data and those of most other workers is that we have eliminated from consideration all of the patients who demonstrated evidence of prior nerve damage. In addition, we followed our patients longer than was done in most of the other studies, in the attempt to learn how much time was required for recovery of nerve function. Although the median duration of treatment and observation until recovery was approximately 9 months, many of the patients recovered only after 20 or more months. 